\title{
The Influence of Heat Treatment on Soft Magnetic Properties of the $\mathrm{Fe}_{60} \mathrm{Co}_{10} \mathrm{Mo}_{2} \mathrm{Y}_{8} \mathrm{~B}_{20}$ Alloy
}

\author{
S. Garus*, M. NabiąeK and J. Garus \\ Częstochowa University of Technology, Faculty of Production Engineering and Materials Technology, Institute of \\ Physics, al. Armii Krajowej 19, 42-200 Częstochowa, Poland
}

\begin{abstract}
This paper presents the results of studies on the magnetic properties of the $\mathrm{Fe}_{60} \mathrm{Co}_{10} \mathrm{Mo}_{2} \mathrm{Y}_{8} \mathrm{~B}_{20}$ alloy. The samples were fabricated in the form of plates by the injection-casting method. The structure of the investigated alloy, in the as-quenched state and after annealing, was verified by using X-ray diffractometry. The magnetization curves as a function of temperature were measured by a force magnetometer. From thermomagnetic curves the Curie temperature of the alloy was determined. As a critical parameter $\beta$ was chosen to be equal to 0.36 for these calculations, it confirmed that the alloys may be considered as ferromagnetic of the Heisenberg type. Additionally, using a vibrating sample magnetometer the magnetization and coercivity field were studied (in magnetic field up to $2 \mathrm{~T}$ ).
\end{abstract}

DOI: 10.12693 /APhysPolA.126.960

PACS: 75.50.-y, 75.50.Kj, 75.30.Ds, 75.20.En, 75.47.Np, 75.50.Bb, 75.60.Ej

\section{Introduction}

An interesting group of ferromagnetic materials are materials with soft magnetic properties produced on the basis of iron, cobalt, boron and yttrium [1-5]. Admixture of other elements allows to modify their properties and to adjust to the requirements of the electricity industry [6-9]. The properties of alloys is also influenced by suitable heat treatment $[10,11]$.

In order to produce amorphous alloy, a very rapid cooling of the molten alloy must be used. The cooling rate is about $10^{5} \mathrm{~K} / \mathrm{s}$. One of the production methods is the injection casting method [5]. Figure 1 shows the necessary equipment used to produce the bulk amorphous materials.

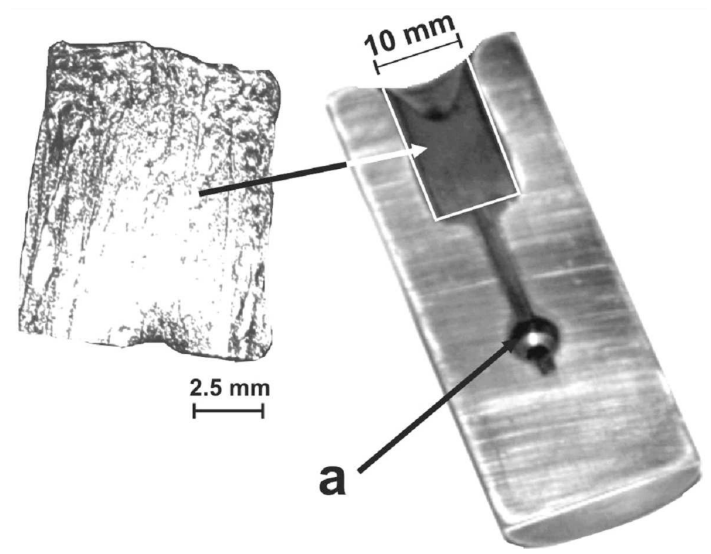

Fig. 1. Prepared sample in the form of plate and radial cooling form with venting channel (a).

* corresponding author; e-mail: sg@wip.pcz.pl
In order to produce the $\mathrm{Fe}_{60} \mathrm{Co}_{10} \mathrm{Mo}_{2} \mathrm{Y}_{8} \mathrm{~B}_{20}$ alloy highpurity ingredients were weigthed with an $10^{-3} \mathrm{~g}$ accuracy. The ingredients were placed in an electric arc furnace. Then obtained high vacuum, after which the protective gas atmosphere at a pressure of $700 \mathrm{hPa}$ was prepared.

Alloy was repeatedly melted in an arc furnace in order to mix the components well. The resulting ingot was placed in a quartz capillary in the apparatus for preparing samples by injection casting method. In the working chamber the pressure of argon was $700 \mathrm{hPa}$. The material was melted in an induction furnace and then injected into a cooled copper form (Fig. 1a) at a pressure of $1000 \mathrm{hPa}$. The resulting samples were in the form of plates with dimensions of $10 \times 10 \times 0.5 \mathrm{~mm}^{3}$ (Fig. 1). Part of the samples was subjected to annealing in vacuum at $700 \mathrm{~K}$ for $1200 \mathrm{~s}$.

The aim of the study was to investigate the effect of heat treatment on the magnetic properties of $\mathrm{Fe}_{60} \mathrm{Co}_{10} \mathrm{Mo}_{2} \mathrm{Y}_{8} \mathrm{~B}_{20}$ amorphous alloys samples such as saturation magnetization, coercive field and the Curie temperature.

\section{Research}

The diffractograms were obtained by using D8 ADVANCE Bruker X-ray diffractometer. Hysteresis loops at fields up to $2 \mathrm{~T}$ were determined using a LakeShore vibrating magnetometer. Thermomagnetic curves were determined using the Faraday magnetic balance.

Figure 2 shows the results of $\mathrm{X}$-rays diffraction of $\mathrm{Fe}_{60} \mathrm{Co}_{10} \mathrm{Mo}_{2} \mathrm{Y}_{8} \mathrm{~B}_{20}$ alloy solidified (Fig. 2a) and after the annealing process (Fig. 2b). The X-ray diffraction patterns for the sample in the as-quenched state (Fig. 2a) and after annealing (Fig. 2 b) consist of a single, broad maximum. This shape of X-ray diffraction pattern is typical for the amorphous materials. 


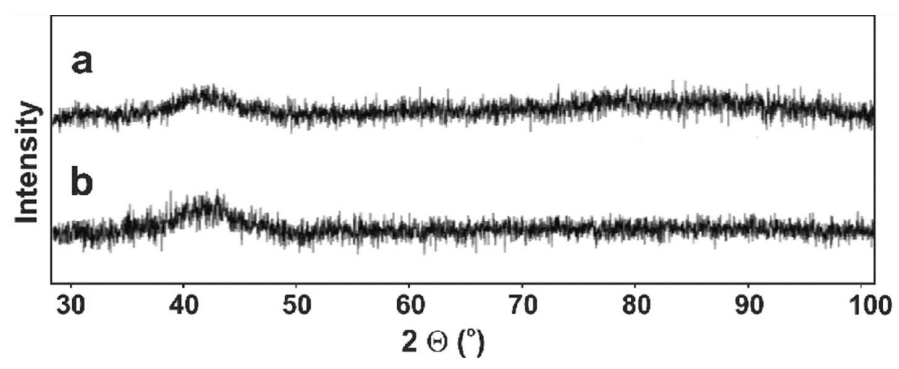

Fig. 2. X-ray diffraction patterns for the investigated alloy in the form of plates in the as-quenched state (a) and after isothermal annealing at a temperature of $700 \mathrm{~K}$ for $1200 \mathrm{~s}$.

Reduced magnetization curves as a function of temperature measured with the magnetic induction equal to $0.74 \mathrm{~T}$ are presented in Fig. 3. The Curie temperature of the sample after solidification was $531 \mathrm{~K}$. The process of thermal treatment caused an increase in the Curie temperature $\mathrm{T}_{\mathrm{c}}$ about 30 degrees to $562 \mathrm{~K}$. As a critical parameter $\beta$ was chosen to be equal to 0.36 for these calculations, it confirmed that the alloys may be considered as ferromagnetic of Heisenberg type.

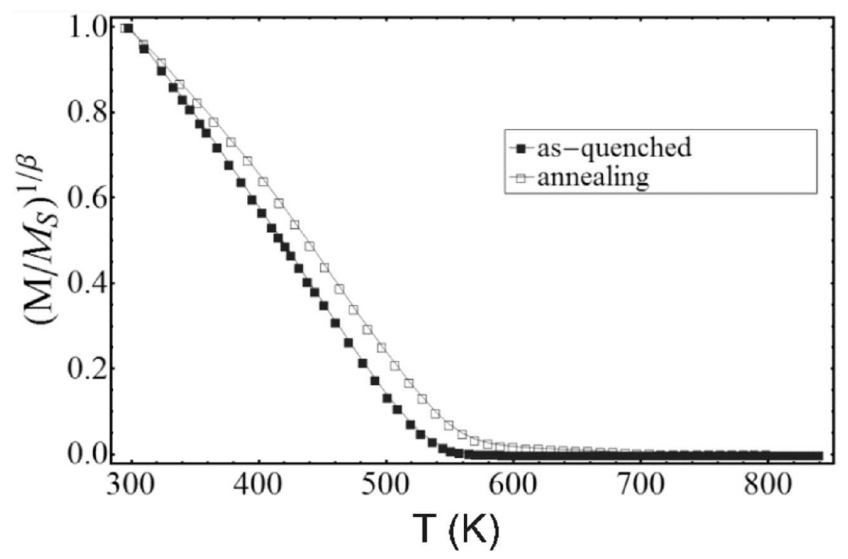

Fig. 3. Reduced magnetization curves as a function temperature measured with the magnetic induction equal to $0.74 \mathrm{~T}$ for the investigated alloy in the form of plates in the as-quenched state and after isothermal annealing at a temperature of $700 \mathrm{~K}$ for $1200 \mathrm{~s}$.

The Curie temperature was increased as a result of the performed annealing process, and the increase is connected with structural relaxations that occurred during annealing at below the crystallization temperature. After thermal treatment that avoids the crystallization process, the free volumes create conglomerates to become quasidislocational dipoles or are released towards the sample surface. As a result, the magnetic interactions between atomic pairs of $\mathrm{Fe}-\mathrm{Fe}, \mathrm{Fe}-\mathrm{Co}$, and $\mathrm{Co}-\mathrm{Co}$ become stronger, which, according to the Bethe-Slater curve, increases the temperature of the ferromagnetic state stability $\left(\mathrm{T}_{\mathrm{c}}\right)$.
Designated magnetic hysteresis loops (Fig. 4) are typical ferromagnetic materials with the soft magnetic properties. Analysis of the static magnetic hysteresis loops indicates that relaxation processes, occurring in the alloy during the isothermal annealing at $700 \mathrm{~K}$ for $1200 \mathrm{~s}$, did contribute to the decrease in the coercivity. It has been found that the coercivity value for the sample subjected to the annealing process decreased by $4 \mathrm{~A} / \mathrm{m}$. The magnetization after the annealing process has not changed substantially. The annealing process, to which the sample was subjected, resulted in the decrease of the effective anisotropy and an increase in the initial magnetic permeability, which also is connected with structural relaxations.

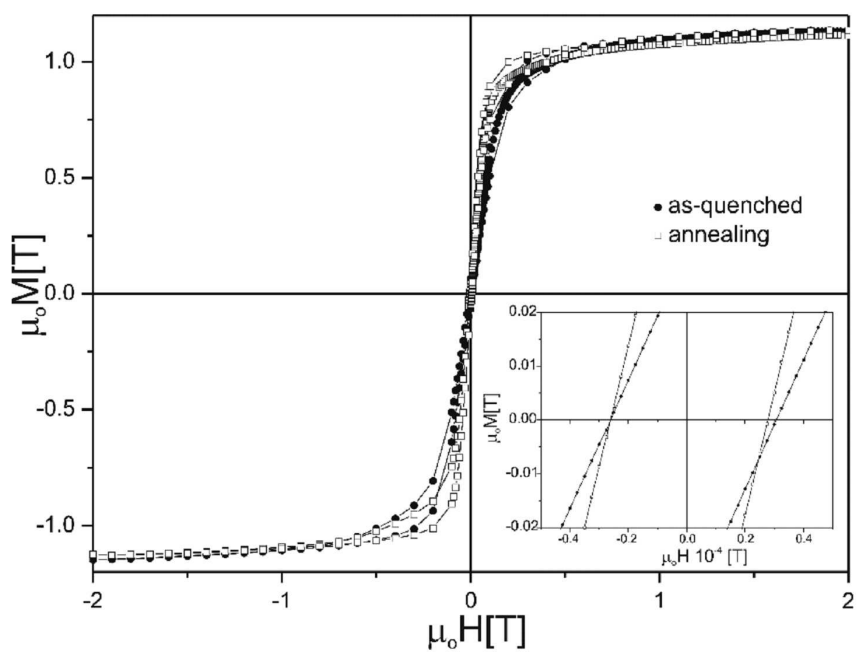

Fig. 4. Static magnetic hysteresis loops, measured for the sample of the investigated alloy in the form of a plate: in the as-quenched state and subjected to isothermal annealing process at the temperature $700 \mathrm{~K}$ for $1200 \mathrm{~s}$.

The results obtained during the study of magnetic properties are listed in Table.

TABLE I

The results obtained from the analysis of the magnetic properties of the $\mathrm{Fe}_{60} \mathrm{Co}_{10} \mathrm{Mo}_{2} \mathrm{Y}_{8} \mathrm{~B}_{20}$ alloy before and after heating.

\begin{tabular}{c|c|c}
\hline \hline \multirow{2}{*}{ Parameters } & \multicolumn{2}{|c}{$\mathrm{Fe}_{60} \mathrm{Co}_{10} \mathrm{Mo}_{2} \mathrm{Y}_{8} \mathrm{~B}_{20}$} \\
\cline { 2 - 3 } & As-quenched & Annealing \\
\hline$\mu_{0} M_{S}[\mathrm{~T}]$ & 1.14 & 1.13 \\
$H_{\mathrm{c}}[\mathrm{A} / \mathrm{m}]$ & 28 & 24 \\
$T_{c}[K]$ & 531 & 562
\end{tabular}

\section{Conclusions}

Samples obtained during the rapid radial cooling had an amorphous structure. The heat treatment provokes structural relaxation, which has significant influence on some magnetic properties of investigated material. The 
relaxation processes, occurring in the alloy during the isothermal annealing at $700 \mathrm{~K}$ for $1200 \mathrm{~s}$, did influence to the decrease in the coercivity. The magnetization of the sample after the annealing process practically has not changed. The observed increase of the Curie point for the sample after annealing at a temperature of $700 \mathrm{~K}$ for $1200 \mathrm{~s}$ may be caused by the change of interatomic distances, which is the result of structural relaxation.

\section{References}

[1] K. Sobczyk, J. Świerczek, J. Gondro, J. Zbroszczyk, W. Ciurzyńska, J. Olszewski, P. Bragiel, A. Łukiewska, J. Rzącki, M. Nabiałek, J. Magn. Magn. Mater. 324, 540 (2012).

[2] K. Błoch, Arch. Mater. Sci. Eng. 64, 97 (2013).

[3] K. Sobczyk, J. Zbroszczyk, M. Nabiałek, J. Olszewski, P. Brągiel, J. Świerczek, W. Ciurzyńska, A. Łukiewska, M. Lubas, M. Szota, Arch. Metall. Mater. 53, 855 (2008).
[4] K. Błoch, M. Nabiałek, P. Pietrusiewicz, J. Gondro, M. Dośpiał, M. Szota, K. Gruszka, Acta Phys. Pol. A 126, 108 (2014).

[5] M.G. Nabiałek, P. Pietrusiewicz, M.J. Dośpiał, M. Szota, K. Błoch, K. Gruszka, K. Oźga, S. Garus, J. Alloys Comp. 615, S51 (2014).

[6] P. Sharma, H. Kimura, A. Inoue, J. Appl. Phys. 100, 083902 (2006).

[7] K. Takenaka, T. Sugimoto, N. Nishiyama, A. Makino, Y. Saotome, Y. Hirotsu, A. Inoue, Mater. Lett. 63, 1895 (2009).

[8] H.J. Sun, Q. Man, Y.Q. Dong, B. Shen, H. Kimura, A. Makino, A. Inoue, J. Alloys Comp. 504, s31 (2010).

[9] H.Y. Jung, S. Yi, Intermetallics 18, 1936 (2010).

[10] J. Yu, C. Chang, D. Karns, G. Ju, Y. Kubota, W. Eppler, C. Brucker, D. Weller, J. Appl. Phys. 91, 8357 (2002).

[11] P. Tiberto, F. Celegato, M. Coisson, F. Vinai, IEEE Trans. Magn. 44, 3921 (2008). 